$\begin{array}{ll}\text { Research Square } & \begin{array}{l}\text { Preprints are preliminary reports that have not undergone peer review. } \\ \text { They should not be considered conclusive, used to inform clinical practice, } \\ \text { or referenced by the media as validated information. }\end{array}\end{array}$

\title{
Exploring the perspectives of healthcare providers on providing HIV prevention and treatment services for Key Populations in Rwanda: a qualitative study.
}

\author{
Gloria Igihozo ( $\sim$ gigihozo@ughe.org ) \\ University of Global Health Equity \\ Junious Mabo Sichali \\ University of Global Health Equity
}

Sandip Medhe

University of Global Health Equity

\section{Rex Wong}

Yale University

\section{Research Article}

Keywords: HIV/AIDS, key populations, sex workers, men who have sex with men, health services

Posted Date: January 31st, 2022

DOI: https://doi.org/10.21203/rs.3.rs-1302080/v1

License: (9) (1) This work is licensed under a Creative Commons Attribution 4.0 International License. Read Full License 


\section{Abstract}

\section{Background:}

The HIV prevalence and incidence among the general population in Rwanda have decreased significantly in the past decade, with only about $3 \%$ prevalence as of 2019 . However, opposite trends are seen among the key populations (KP). The prevalence among commercial sex workers is as high as $51 \%$, and the HIV rates among this group continue to rise. While the prevalence among key populations remains high, their adherence to HIV treatment is low compared to the general population. Healthcare providers play a vital role in ensuring key populations' access to HIV treatment, adherence, and program retention. This study aimed to explore the experiences of healthcare providers in providing HIV services to key populations in Rwanda.

\section{Methods:}

A qualitative phenomenological study was conducted with nurses, doctors, social workers, and psychologists who provide HIV services in health facilities in Rwanda. In-depth interviews were conducted using a semi-structured interview guide. Transcribed and translated data were coded according to a structured code book. All data were organized and analyzed using Dedoose software (version 8.3.35).

\section{Results:}

Interviews with 18 healthcare providers were conducted; participants included 1 doctor (5.6\%), 5 social workers (27.8\%), and 12 nurses (66.7\%). All participants had worked with key populations, especially commercial sex workers and men who have sex with men. Three overarching themes emerged from the interviews: healthcare providers' intrinsic feelings affect the ways they provide HIV services to key populations, key populations face a multitude of challenges related to accessing treatment and preventing the spread of HIV, and a more comprehensive and sensitive approach should be used to improve HIV services for key populations.

\section{Conclusion:}

Healthcare providers expressed difficulties in providing services to key populations as they tend not to adhere to treatment and prevention guidelines, caused by some structural barriers, their lack of trust in the system, and the discrimination and abuse they have faced. More comprehensive services including clinical, financial, and psychosocial support from trusted sources are needed. Some important policy changes may be needed to allow KPs to purchase community-based health insurance.

\section{Introduction}

Rwanda has about 350,000 people living with HIV, translating to $3 \%$ prevalence - with $3.7 \%$ among women and $2.2 \%$ among men [1]. Since the first reported HIV case in 1983, the government of Rwanda has developed programs and policies, including setting National HIV/AIDS targets, introducing voluntary testing centers and provider initiated testing, creating programs for prevention of mother-to-child transmission, voluntary medical male circumcision, distribution of condoms, nation-wide access to Antiretroviral Therapy and behavior change communication, in attempt to reduce new infections [2,3]. Consequently, there has been significant decreases in HIV prevalence and incidence among the general population in the past decade [4].

However, opposite trends exist among the key populations (KP) - sex workers, men who have sex with men (MSM), incarcerated people, adolescents, transgender individuals, and people who inject drugs. The HIV rates among these groups continue to rise and remain high globally and in Rwanda [5,6]- with a country-wide HIV prevalence of $51 \%$ among 
commercial sex workers, over 10\% among prisoners, and 4.8\% among MSM $[7,8,9]$. As for transgender women and injection drug users in Kigali, the prevalence stands at $10 \%$ and $9.5 \%$ respectively $[10,11]$.

The HIV/AIDS prevalence is generally high among KP around the world, implying more effective prevention and treatment efforts are needed for these communities $[5,12,13,14]$. Trends in HIV infections within KP have also shown that access to prevention and treatment programs, and adherence to HIV treatment are lowest among KP in many countries, including Rwanda $[5,15,16]$. It is important, therefore, to understand the factors hindering access to treatment among KP in Rwanda in order to design more effective programs and interventions.

In Rwanda, healthcare professionals (HCPs) such as nurses play a vital role in ensuring access to HIV treatment, adherence, and program retention $[17,18,19,20]$. Working closely with individuals living with HIV, their perspectives on the barriers that impede treatment could be used to inform viable policy and program design [21,22]. Studies conducted in Rwanda have focused on the prevalence and incidence of HIV and associated factors among specific KP groups, and on the perception of healthcare providers (HCP) and community members on Pre-Exposure Prophylaxis and HIV transmission [7,8,9,23,24]. To our knowledge, no studies identifying the perceptions of HCPs on the provision of HIV treatment and prevention services to KP have been conducted in Rwanda. In order to develop context-specific interventions to reduce HIV transmission and increase service access amongst KP, the perspectives of HCPs on existing HIV services are crucial. This study, therefore, aimed to explore the perspectives of healthcare professionals on HIV treatment and prevention services for key populations in Rwanda.

\section{Methods}

\section{Design}

A qualitative phenomenological study was conducted to explore the perspectives of HCPs working in HIV clinics in Rwanda. In-depth interviews were conducted in urban, suburban, and rural health centers in four districts of Rwanda: Gasabo, Kicukiro, Nyarugenge, and Gicumbi.

\section{Sample and sampling}

Purposive sampling was used to select nurses, social workers, psychologists, and doctors who provided HIV services at the study sites. Participants were sampled until theoretical saturation, the point at which no new information is emerging from participant responses. Only HCPs who had served at least one person from a KP group and had at least one year of work experience in delivering HIV services were included in the study.

\section{Data collection tool and method}

Data was collected using a semi-structured interview guide that included six open-ended questions, with probes. The questions were developed based on other similar studies [25,26]. The questions in the interview guide were related to the experiences of HCPs serving different KP groups, the challenges and facilitators when providing HIV services to KP, as well as the necessary resources and skills needed for HCPs to better serve KPs. The interview guide was developed by the research team in English and translated to Kinyarwanda - the local language. The interview guide was pre-tested with eight lay persons to check for understandability and with five HIV healthcare providers working outside the sample sites to test for context validity. Modifications were made based on the feedback from the pre-tests before the actual data collection.

Two data collectors who were trained in conducting in-depth interviews were used in this study. A one-day training was provided to orient them on the study objectives, data collection protocol, ethical considerations, and interview techniques. 
Additionally, the data collectors were a mix of men and women, to ensure that we were concordant with the population in which this study was conducted.

The participants recruitment took place between May and July 2020, at the study sites. The directors of the study sites were contacted by the research team and a detailed explanation of the study was provided to them. After the directors agreed to allow the research team to conduct the project within their facilities, they provided a list of healthcare providers at their facilities' HIV clinics. The research team approached the potential participants who fulfilled the selection criteria via telephone and scheduled a time and location of the participants' choice to conduct the interviews.

Consent to conduct and record the interviews was sought after detailed explanation of the study was provided to the participants before the interview. All interviews were conducted in Kinyarwanda, as preferred by the participants, in a private space to ensure participants' privacy.

Each interview lasted for approximately 45 minutes. The principal investigators listened to the interviews and reviewed notes at the end of each data collection day to determine if saturation was reached, adjust the questions and probes as needed, and/or identify any areas of improvement in the way the interviews were being moderated. The study team also met twice a week during the data collection period to review the findings and revise the interview guide as needed.

\section{Data analysis}

All audio recordings were transcribed verbatim and translated into English. A preliminary codebook was created by the research team after open reading of 6 transcripts. The investigators first coded independently and met as a team to resolve any discrepancies through discussion and revision of the definition of the codes. After finalizing the codebook, all transcripts were coded inductively and iteratively using Dedoose software (dedoose 8.3.35), by the research team. Memos were written by the research team during both data collection and data analysis, to identify themes arising from the data. The coded transcripts were grouped into themes and representative excerpts were included in the findings.

\section{Results}

\section{Participant Characteristics}

Eighteen healthcare providers from 6 ( 4 urban, 1 suburban and 1 rural) health facilities participated in the study; with 1 doctor (5.6\%), 5 social workers (27.8\%), and 12 nurses (66.7\%), with an average age of 45.6 years. Fourteen $(77.8 \%)$ participants were female, and four (22.20\%) were male. On average, participants had 10 years of working experience in HIV service delivery and 11 (61\%) of them had a bachelor's degree. All participants had worked with key populations, especially sex workers and MSM, and all identified themselves having religious beliefs (Table 1).

\section{Table 1}

Demographic characteristics of study participants. 


\begin{tabular}{|lll|}
\hline Characteristics & & $\mathrm{n}(\%)$ \\
\hline Sample size & & 18 \\
\hline Age (years) & Female & $14(77.8 \%)$ \\
\cline { 2 - 3 } Work experience (years) & Male & $4(22.2 \%)$ \\
\hline Highest education level completed & Mean (range) & $45.6(36-64)$ \\
\cline { 2 - 3 } & Secondary and post-secondary diploma & $7(38.9 \%)$ \\
\cline { 2 - 3 } & Bachelor's degree & $11(61.1 \%)$ \\
\hline Profession & Nurse & $12(66.7 \%)$ \\
\cline { 2 - 4 } & Social worker/psychologist & $5(27.8 \%)$ \\
\cline { 2 - 4 } & Doctor & $1(5.6 \%)$ \\
\hline Location & Urban & $12(66.7 \%)$ \\
\cline { 2 - 4 } & Suburban and Rural & $6(33.3 \%)$ \\
\hline Religious beliefs & Yes & $18(100 \%)$ \\
\hline
\end{tabular}

Three overarching themes emerged from the interviews:

Theme 1: HCP's intrinsic feelings affect the ways they provide HIV services to KPs.

Theme 2: KPs face a multitude of challenges related to accessing treatment and preventing the spread of HIV.

Theme 3: A more comprehensive and sensitive approach should be used to improve HIV services for KPs.

\section{Theme 1. HCP's intrinsic feelings affect the ways they provide HIV services to KPs.}

Respondents expressed that they experienced a wide range of feelings and emotions when treating KP patients - from seeing them as friends, to disapproving their lifestyles- that could affect the ways they provide services to KP. Their personal views and feelings were influenced by their religious beliefs, their social up-bringing as well as the social and professional expectations imposed on them. Such intrinsic feelings inevitably affected their attitudes and behaviors when providing services to KPs.

\subsection{HCPs saw KPs as their friends, making KPs feel at ease when seeking HIV care}

A number of respondents said they had no problems when providing healthcare services to KP. In fact, they considered some of them as friends, especially if they have been providing services to them for a long time. Although sometimes they felt sad and discouraged, they strongly felt services for KP must be continued. They believed that their positive attitude towards KP made the KP patients feel comfortable and at ease when they came for care - without the fear of being judged or treated differently. This friendly yet professional rapport could increase KPs' adherence and involvement in their own HIV care. 
"It doesn't make me feel bad in any way [serving sex workers]. Most of the times you find that the sex workers who come here I see them as my friends.... You talk to them and show them that you are putting yourself in their shoes so that you manage to resemble them. I cannot stop doing that [giving them services]." (Female, social worker, 0007).

"For me, yes I am a believer, but a medical professional goes beyond all that. And if I was even to consider my faith, I would be in a good position of helping those KPs. Did Jesus chase sex workers? No. Then who am I to chase them? I just give them services [sex workers] regardless of my beliefs or anything else. What tells you she won't change for good tomorrow if I give her good services today?" (Male, nurse, 0028).

"Yes, I have beliefs, but I am not a slave to religion. I know that believers say, "MSM bewitched you", but I know God is merciful. Everyone has their mistakes and qualities. So, in front of God, if you judge someone and say, 'that one is cursed', yet you are not the God who created him... You may find that he has gone to heaven before you, while you're busy condemning them and calling yourself righteous. So, all I do is to give services to people as I have learned- without distinction. I will never say 'I will only serve others and not MSM' and yet he is sick and needs medical care, no. Refusing services to MSM would be, I think, committing a graver sin. So, for me, religion is not a challenge." (Female, social worker, 0049).

\subsection{HCPs had internal conflicts when treating KP patients}

Not all HCPs, however, shared the same undivided devotion towards KPs. Some expressed internal conflicts when treating $\mathrm{KP}$ patients, stemming from their cultural and religious views on gender and sexuality. Homosexuality and commercial sex work, according to their cultural up-bring and religious beliefs, are not acceptable and are often seen as abominations. These negative perceptions, in general, were stronger against MSM than on sex workers. At the same time, although HCPs expressed that they believed that KP's lifestyles went against biblical teachings, they maintained that their religious beliefs still called on them to help the marginalized with love and compassion, without judging them. Some also felt it was their professional and social responsibilities as healthcare providers to treat the KPs in order to prevent the spread of HIV.

"There are things they [MSM] do that are not right in my beliefs. When I strip myself of who I am [as a healthcare professional] and I go into my beliefs, there are things they do that are not right. I believe that God created man and woman to reconcile their union. I do not believe that a woman should have sex with a woman, or a man should have sex with a man. But we are in an evolving world, [these] things have been normalized, people have treated them as normal [occurrences]. The real sin is, there is a term that we call 'breastfeeding sin' [in Kinyarwanda, it roughly translates "the sin that you commit due to you indirectly encouraging the sin of another"]. When you feel that doing something is not a problem, it doesn't mean anything to you, but before God we have sinned. But what I also believe, on the other hand, a human being has undisputable rights." (Female, social worker, 0013).

"In the real Christian faith, fornication is prohibited because it is a sin. Homosexuality is another [sin]; even in the Bible, you find that Sodom and Gomorrah were destroyed because their homosexuality made God angry. In fact, I receive them, but it's like a job. In reality, I don't support those things. But you give them counseling so that they may handle the situation. In my beliefs, I don't agree with that [being MSM]. At first, I refused to do it [give them treatment]. I was wondering about the things I've been required to do yet I don't agree with it, but I calmed down. There was no other choice. I did it. But in my beliefs, I don't support it." (Female, nurse, 0040).

"It is sometimes discouraging [treating KPs as they continue to do activities that expose them to HIV], but we have to give them services no matter what. Refusing to give them service, means that they might transmit the disease to another person, who might in turn infect more people. We have to give them healthcare services in order to stop the spread of the disease. Being discouraged to serve the KPs is dangerous because it is like telling them: go and continue. Tomorrow they might infect my child, my sibling, and any other person... you might end up finding that the whole country is infected because we got discouraged and stopped caring." (Male, nurse,0028). 


\subsection{Some HCPs simply refused to receive KPs, especially MSMs, because of their religious beliefs}

Religious beliefs had a huge influence on the attitudes of HCPs toward KP. Some respondents believed the KP' lifestyles were against their religious and biblical teachings; providing treatments for the KPs was encouraging "sin". With such belief, some refused to provide treatment for KPs, especially MSM.

"Those things [men sleeping with other men] are not in line with the word of God. This means that I consider that [homosexuality] to be another illness, they are abnormal things. If it were better, the person would luckily heal and do what God has planned for us to do ... In the context of mental illness, it [being MSM] is also an illness." (Female, nurse, 0037).

"Based on my beliefs, accepting those MSM is a challenge. Things regarding homosexuality are usually found in urban areas, it is not found in rural areas. They are unusual things. But I don't even wish to work with them, I think I wouldn't even know how to start receiving them and serving them because I don't know how I could exactly deal with them. It would be very hard for me to receive them because we are not used to them in our culture. It is not even supposed to be a thing that we take as normal because it [being a MSM] is a trendy behavior." (Female, nurse, 0052)

Overall, all our respondents had religious beliefs. While some could overlook the conflict and dedicate themselves to providing services to KPs, many had internal struggles. And a few just plainly saw homosexuality as a sin and did not want to provide any services to MSM.

\section{Theme 2. HCPs faced a multitude of challenges in providing HIV services to KPs}

HCPs found some unique challenges when providing HIV services to KPs. Many KP patients delayed seeking care and did not adhere to the treatment protocol. While delays in seeking care and poor adherence also happened in the general population, different root causes were identified among the KPs. The challenges and barriers faced by the KPs stemmed from personal, work, social and financial issues, impacting their access, retention, and adherence to treatment, and eventually their health outcomes.

\subsection{KPs work schedules and lifestyles affected their access to and retention in HIV services}

HCPs expressed how logistical challenges including sex workers' schedules and the frequent relocations of KP contributed to a high attrition rate in HIV services and poor adherence to prevention and treatment. Many sex workers worked at nighttime and often struggled to attend follow up appointments during the day or take medication at the prescribed time. Some KP, especially sex workers, were reported to sometimes not to take the medications, as they could not bear the side effects. Feeling nauseous and low in energy were said to have been affecting sex workers' ability to find clients and generate income. Furthermore, they often moved to different towns or cities unexpectedly, due to a lack of job stability, and HCPs often could not follow up with them, contributing to poor treatment outcomes.

"When you see that [medication] is not having an impact, you have to think that this person may not be taking the medication. Because, if a person is engaged in sex work, she often spends the night on the street." (Female, nurse, 0043).

"The main challenge is that these key populations are mobile people. For instance, sex workers, you give her an appointment and she doesn't show up. We call her, and she tells us she has moved to another place because in our area she could no longer find customers. She would say, 'I moved to another place where I find customers and so it is difficult for me to come 
back [to the facility].' That is a serious challenge when you cannot continue to follow up; it is difficult to know if she seeks health services elsewhere." (Male, nurse, 0028).

\subsection{KPs fear attending HIV clinics}

Another major challenge identified by providers was fear. HCPs mentioned that KPs, especially MSM, were fearful of attending HIV services because of social, cultural, and legal factors. From their experience, many HCPs stated that MSM patients delayed seeking HIV treatment. Their previous experiences of being mocked or shunned in other facilities have left MSM feeling uncomfortable, resulting in delays in seeking care. Consequently, the HCPs reported that the majority of MSM patients had to be referred to more advanced care. Further, providers expressed that when MSM patients came for HIV services, many didn't want to interact with other patients or even HCPs. MSM were also reported to fear that disclosing their sexuality and lifestyle could result in discrimination and prejudice from their families and HCPs, because of the social and cultural norms surrounding sexuality and gender.

"MSM are in fear. One MSM told me, 'There are many [MSM] in the villages but they would not come to see the doctor. They suffer from sexually transmitted infections and are ashamed of [showing up for] treatment.' These are the ones who need to be cared for, to be treated, and to be courageous. What I have seen is that they hardly go for treatment." (Female, nurse, 0043).

Most of them have encountered that challenge [hostility]. When I ask them, they tell me 'Yes, I was sick, but I was afraid to come to seek medical care...' and, as a result of those delays in seeking care, we refer them to [district] hospitals for advanced care. We have a serious challenge because many of the MSM cases we receive, we have to transfer them. And then, when we transfer them to let's say to [name redacted] hospital, they sometimes refuse to go. They say, 'they don't know us there' and so they sometimes end up not accepting the transfer." (Female, social worker, 0049).

The fear of being incarcerated was another reported main challenge for KP patients contributing to delay or choice to not seek HIV services. There were incidences where law enforcement officers targeted and jailed KP when they presented themselves to health facilities, causing KP to distrust HCPs.

"I realized these people are confronted by the law enforcement more than they receive healthcare services. They [law enforcement] take them from the streets and put them in jail and it affects our work. For instance, we once invited new sex workers to get healthcare services but only a few showed up on the first day because they were afraid that the intention was to put them in jail rather than to give them healthcare services ... It is difficult for us to meet sex workers and people who inject drugs because they fear that the agenda is judicial, not medical. We need to work together to make them comfortable so that they come here without fearing that we will turn them in to the authorities. They think we are trying to trick them so they would be taken into custody. We need to find a way to reassure them and remove their fear that coming to get healthcare services will land them in jail." (Female, nurse, 0004).

\subsection{KPs face financial challenges which impacts their ability to seek care}

Financial barriers and the lack of health insurance were other identified treatment barriers. Although HIV services are free for all in Rwanda, treatment for HIV comorbidities such as diabetes is not. HCPs mentioned that when most of their KP patients did not have health insurance, they either had to pay out of pocket or were unable to seek care. The structural barriers within the community-based insurance system, coupled with negative perceptions towards KPs were causing KP to be unable to get health insurance. The community-based health insurance system in Rwanda is directly linked to the socio-economic categories of households. These categories are used to determine how much premium individuals should pay for health insurance. Categories are only given to households, not to single individuals. Respondents reported that some KPs had been 
disowned by their families, and their names removed from the household list. Without being listed in a household, they could not claim the socio-economic category, and in turn, could not get health insurance. Providers mentioned that there were instances when KPs went to government facilities asking to be registered for socio-economic categories but were mocked and discriminated when government officials found out these individuals were sex workers or MSM.

"The challenge is when we find him/her with other diseases which require medical insurance [mutuelle de santé], and yet they cannot afford health insurance. They cannot afford care for other diseases that require further treatment, without medical insurance." (Male, nurse, 0031).

"Sex workers and MSM do not have ubudehe categories [socio-economic categories] like other Rwandan citizens. MSM also kept telling me that they were denied socio-economic category services since they are MSM. It is difficult for MSM and sex workers to get socio-economic categories from local authorities. When MSM and sex workers go to ask for categories, the local authorities put them to shame in public. The official can say 'You, prostitute, are also here to look for a social category? And you guy who transformed yourself into a woman, you also want a social category?"' (Female, social worker, 0049).

\subsection{The professional hazards associated with sex work were obstructive to the HIV services}

Sex workers are known to be at high risk of being abused, being exposed to physical violence, and contracting HIV. When offered a relatively large amount of money to have unprotected sex with clients, sex workers were often left with no choice but to accept. They also often faced extremely violent and abusive clients. Providers expressed that such traumatic experiences, stemming from the nature of their work, often caused sex workers to become defensive and resulted in distrusting people, including HCPs. Consequently, they eventually stopped coming for treatment or refused to take medications.

"For instance, one [a sex worker] may tell me that "I use condom but sometimes a client comes and finds me hungry and deprived and tells me, 'I have so much money to give you' and so we won't use condom, and I accept!" Why do they accept it? Because she didn't eat the previous night and wants what to give to her children; the situation pushes her to the limit. She wants to use a condom, but her client doesn't and is paying extra." (Female, nurse, 0004).

"The practices obliged by their [sex workers'] clients also put them at very high risk ... they have clients who oblige extraordinary practices that are dangerous. Sex workers sometimes come with wounds on the body because a client has beaten her or broke her arm ... and this violence perpetuated upon them creates a defensive character; they do not have a sense of love ... It then requires us to use extra energy [to treat them] since they also do not respond to medical visits. We have many cases of them who no longer come to take medicine [for that reason]." (Female, social worker, 0049).

Many HCPs mentioned that because of these traumatic experiences, sex workers sometimes had negative behaviors and attitudes such as being impatient, aggressive, disrespectful, and insulting HCPs. Providers went on to explain how these perceived behaviors and attitudes aimed towards them were often a major challenge they faced when providing HIV services to this group. For some respondents, they expressed that working with sex workers when they deemed them to be impatient was a challenge because they had to overlook this so as to help them adhere to prescribed treatment. Other respondents also mentioned that the sex workers they received were aggressive and reported that this made these respondents uncomfortable when they had to receive sex workers in their HIV services.

"Often, when someone is engaged in prostitution, you realize that they have bad behaviors like insulting, and daring to confront a doctor. That really requires that you try to be patient so that you can help her to take the medication." (Female, nurse, 0001). 
"The second challenge is that sex workers are not patient; they are aggressive with their words, are disrespectful, and say hurtful things. Only a few are respectful. But for many of them, it is difficult to cooperate [with them] and sometimes this makes me uncomfortable." (Male, nurse, 0010).

Overall, respondents reported that there are a myriad of challenges and barriers hindering KP's access to HIV treatment and prevention. The mobility of KP, working during the night, fear of discrimination and incarceration, financial challenges and lack of health insurance, the health seeking behaviors of MSM, challenges associated with sex work, and HCPs' perceived aggressive behaviors of sex workers were some of the factors believed to be major challenges and barriers to successful HIV prevention and treatment among KP groups. These factors combined were said to contribute to low treatment adherence, higher attrition of KP in HIV clinics, and inability to follow HIV prevention guidelines.

\section{Theme 3. More comprehensive and sensitive approach should be used to improve HIV services for KPs}

Many respondents provided recommendations on efforts and services needed to facilitate KP in accessing better HIV services. Since some of the challenges faced by KP were unique, HCPs suggested that the approach should be multi-prong and sensitive to their needs.

\subsection{Trust is an important factor when facilitating KP to access HIV services}

Channeling services through sources that KP are familiar with, and trust, was a key way to encourage them to access the services. When HCPs reached out to KP through trusted mediums, more people were willing to listen to medical advice. Providers mentioned that KP tend to listen to and trust their peers, their group leaders, people from their treatment groups, and other KP. HCPs stated that partnering with NGOs that support KP could also improve access to HIV services for KP. These NGOs not only provided free services KP needed, but also identified KP from the communities and connected them to health facilities for HIV testing and care.

"It [having team leaders] helps us and makes it easier for us. When we look for them [KP] in their workplaces or in their community, they don't listen to us. You can tell that they freak out to the extent that they don't trust us. But when look for them through team leaders, many of them come because they are sure that the services we provided to their friends will also be provided to them. That helps us with the follow up because they believe that what we do will be of help to them" (Female, nurse, 0052).

"There are organizations we work with, who partner with us to facilitate access to health services for key populations. There is one called HDI [Health Development Initiative], that works with MSM, and SFH [Society for Family Heath], that follows up with girls who do sex work. So often, they are the ones who give us these people because we have a partnership. They bring them [KP] in, we receive them, we either do the regular follow up, or start them on medication. They're the ones who connect us with them." (Female, nurse, 0040).

"Sex workers have an organization [Project San Francisco] paying for their health care [HIV] services. They get medicine for free and others who are HIV negative, they get preventative medicine. We provide the services, make a bill, give it to the project and they pay for it. There is no [HIV] service we provide that they pay for themselves." (Female, nurse, 0004).

\subsection{KPs need more specialized health services}


As members of KP faced unique challenges, they needed more tailored and specialized services. Home visits, individual counselling, and education could facilitate access to healthcare services. All HCPs expressed that counselling was one of the effective ways to promote behavioral change among KPs and make them take preventive measures more seriously. Counselling also gave KP patients opportunities to open up about the different problems they faced. In health facilities where counseling services were provided, providers expressed that the retention and treatment adherence rates among KP were generally higher, and thus had more desirable outcomes. Home visits were another effective way to facilitate HIV treatment for KPs, as home visits could give HCPs the opportunity to identify social and environmental factors that KP patients faces and could, therefore, find ways to address them.

"The counseling changed their [key populations] mindsets, especially when it comes to the subject of HIV/AIDS. Especially for the MSM, they told us, 'Before, I did not care about using condoms, I would only use lube because I had been told that I could not get infected when I use lube.' When we tell them that condoms are important in prevention, many understand and take condoms home. Later when they returned, they told us, 'I used a condom; I am now familiar with how to use it."' (Male, nurse, 0028)

Many of them [sex workers] with that attitude [not taking medication] are adolescent or young, our team visits them at home, discusses with them ... and from that, we treat them from the root cause. From those home visits we identify many problems they faced at home, from which we start providing them counselling and social work." (Male, doctor, 0019)

All HCPs expressed how having specialized HIV services for KPs or having a select few HCPs trained in providing HIV services to KP groups could improve their services. This could ensure sufficient time is allocated when treating KPs and, in turn, could enable HCPs to build a trusting relationship with KP patients. There were, however, mixed opinions about providing HIV services to KP in locations separated from the general population. Some HCPs who worked in facilities where services were provided in separate locations for KP said that it eased KP's anxiety and resulted in more KP patients coming for HIV services. They also said they could follow up their cases more effectively. Some respondents, on the other hand, considered that this would further isolate KP.

"[Sex workers] need special treatment because they are also in a specific situation. I think there should be people in charge of them specifically, so that they help them to be comfortable and confident enough when they seek health services. Even though I told you that we receive a number of them, there are others who don't show up, who hide. If a specific unit for them is created, it would help us to help them. A team trained to provide such services should be in place to support them, so that their lives are improved." (Female, nurse, 0004).

"We have separate services for them [key populations], the health center officials set up a schedule of providers who will receive them on that particular day. This was done because when they are mixed with the general population, it is not good, neither for them nor for us as healthcare providers. The reason for this is that, especially for sex workers, they are victims of STDs ... that is where to focus [treatment], to know the cause and solve the problem. They are sex workers, and they have sex with who? With men, husbands from families, and this makes them bridges [of HIV] in the society. It is, then, important to receive them separately for special care in order to counsel them and get all that information to reduce the spread of the disease." (Female, social worker, 0046).

All respondents mentioned that additional resources to facilitate HIV service provision to KP were needed. HCPs said they needed to build their skills, such as counselling skills, to receive different KP groups. Respondents expressed that they often did not feel comfortable receiving KP because they did not know how to manage their cases. Some participants also expressed that such trainings should be extended to government officials and parents, as KP also faced discrimination at home and in other services, and any negative experience they face could impact their treatment seeking behaviors. Respondents also said that more frequent supervisions by experienced HCPs would help identify potential areas for improvement. One HCP also suggested creating a database to map out the locations of KP, so HCPs could go to their communities and encourage them to attend HIV prevention and treatment services.

Page $11 / 20$ 
"We need training and advocacy [for key populations] at all levels! Leaders, health officials... the training should be given to all levels because mindsets are different. We all need to have the same understanding with regards to MSM because sometimes, parents traumatize their children. Many tell us, 'they [parents] often beat me because of this [being MSM].' We have to hold each other accountable to prevent the spread of all these diseases, because if we do not protect these KP from diseases, we will be exposing ourselves as well." (Female, social worker, 0049).

"They have trained only a nurse and a social worker about healthcare services to the KP and sex workers. It would be better to also train all other staff, especially clinicians such as heads of departments, doctors, counsellors and social workers so that when they [patients] come, they get the services from any professional who is available without having to call the trained person or tell the patient to come back when they [a trained person] will be available." (Male, nurse, 0010).

"I think for people who planned this research, they should do a study or a mapping of those people [MSM] so that they are documented. Because I think for them, they have places where they meet, they have networks, they have associations, one way or another. It would be good for us to know 'if I need these people, I will meet them here or there.' It would be good to have their data." (Female, nurse, 0022).

\subsection{Other supportive services are needed to facilitate KP to access HIV services}

To ensure KP continue attending and adhering to HIV treatment, only providing clinical services was not sufficient. All our respondents mentioned that KP needed more supportive services, including economic empowerment, psychosocial and financial support, employment opportunities, and nutrition support. Some providers used examples of how the transportation allowance provided by their HIV clinics to KP had encouraged more KP patients to attend. Respondents suggested that these supportive services would not only facilitate treatment adherence but would also promote the wellbeing of KP.

"Even when they come for follow ups and the sponsors give them transport fare, you see them happy, they come in large numbers. They even talk to each other. If someone who had stopped attending the service hears 'if you go, they will give you transport fare', they come immediately ... you can't get them by yourself. But when the team leader tells them that they will get transport money, they come happily and come in large numbers." (Female, nurse, 0043).

"Drug users don't have sponsors [they don't receive any other support] ... they get medication, but their follow up is very difficult. They often miss appointments." (Female, nurse, 0043).

I do not have figures but those [sex workers] we meet tell me that it is because of life hardships that they found themselves in sex work. Their problems need to be dealt with in a psychological, social and economic way for them and their families." (Female, nurse, 0004).

"Most importantly, financially support the patients [sex workers] to afford good nutrition so that they can cope with [the side effects of] the medicine. This is important because patients we visited were not carefully taking the medication due to economic deprivation [food insecurity] ... when a patient can at least find something to eat, she regains hope and begins to respect medical visits." (Male, doctor, 0019)

Overall, assistance and referrals from a trusted body could facilitate the KPs' access, attendance, and adherence to HIV services. Separate services and HCPs for KP groups, capacity building programs to all levels were suggested. More comprehensive interventions, other than clinical services, including nutrition support and financial empowerment would encourage KPs to seek HIV services and improve their well-being.

\section{Discussion}


This study aimed to explore the perceptions of HCPs on the provision of HIV services to KP in Rwanda. Our results highlighted three themes that denoted the factors impacting HIV care for KP and opportunities for developing contextspecific HIV services that could address the needs of KP groups.

\section{HCPs were torn between their professional duties and personal views}

Medical professionals have the call of duty to serve the population. A core element of professionalism among health care workers, as stated by the American Board of Internal Medicine, is altruism - 'the best interest of patients, not self-interest, is the rule" [27]. However, being obligated to their professional duties did not translate to them being void of their personal feelings. The cross-path between their professionalism and cultural and religious beliefs caused many HCPs to face some internal struggles. Some HCPs held negative attitudes towards KPs - they were sinners, they were abnormal. This kind of culture-informed perception, however, is not unique to Rwanda. A study conducted in Uganda, a neighboring country, showed that HCPs held similar views towards MSM and sex workers; providers in this study expressed their reluctance to receive them in their facilities [28]. Like in this study, HCPs in the Matovu et al. study had a stronger aversion towards MSM than sex workers, possibly because homosexuality is believed to go against cultural norms and religious values surrounding sex and sexuality. In both studies, homosexuality continues to be viewed and referred to as culture imported from elsewhere; this is a concept that continues to alienate MSM in society as well as in health facilities, labeling them as "others".

Although Rwanda is one of the few countries in sub-Saharan Africa that does not criminalize homosexuality [29], the intrinsic feelings and biases of HCPs towards MSM pinpoint to a deeper and graver barrier to HIV services. It speaks to the fact that not criminalizing homosexuality is not enough to guarantee equal rights and equal access to health services for MSM. Hence, systems still need to be in place to ensure equitable access to health services, and to address HCPs' intrapersonal barriers that might drive MSM and KP away from these services. The internal struggles of HCPs also provided a glimpse into the severity of the stigma MSM face, as this might be more intensified within the general population [29]. Thus, programs and policies that aim to change negative perceptions about MSM in Rwanda and address the stigma they face within health facilities and the community at large, are of utmost importance.

Studies in sub-Saharan Africa, including in Rwanda, have also shown how religion and culture-induced negative perceptions towards KPs, especially MSM, could result in stigmatization and implicit bias against KPs, contribute to KP patients losing trust in HCPs and in the healthcare system, lead to reduced access to HIV services among KPs, and lead to increased risky sexual behaviors within this community [30,31]. Discrimination and stigma reported in this study, that drove KPs, especially MSM, away from HIV services in health facilities, have been documented in various contexts in sub-Saharan Africa $[32,33,34,35,36]$. Therefore, these findings call for a need to research and understand how HIV programs in Rwanda can be responsive to the various forms of stigma and biases that KPs face in society and within health care facilities. Additionally, the clinical environment where KPs seek care needs to be prioritized in programs, strategies, and policies that address the needs of KP, especially MSM, to ensure that it does not negatively affect willingness to seek HIV services.

One finding that's unique in this study was that some respondents had mentioned that some KPs' behaviors and attitudes towards HCPs created a barrier between the two parties, suggesting that communication barriers on both sides impacted the experiences and services that KPs had in health facilities. The importance of communication strategies between HCPs and KPs in improving care and promoting the well-being of KPs, therefore, cannot not be underestimated [15]. These realities, thus, highlight a crucial need for HIV programs across Rwanda and East Africa to develop mechanisms through which providers can be trained on effective strategies to address communication barriers impacting KPs' access to HIV services.

\section{HIV Services Challenges and Facilitators}

Many challenges hindering HIV services for KP identified in our study such as poor adherence to treatment, low program retention, financial hardships, poor nutrition, high mobility, legal and structural barriers, fear, and mistrust in the healthcare 
system are similar to those identified in other contexts [37,38,39,40,41,42]. The need for comprehensive, holistic, and KPfriendly HIV services is clear. Such services not only would promote the physical health of KPs in Rwanda, but also their mental and social well-being as evidenced by success stories from different countries across the globe [43]. Further, since KPs in this study were reported to have higher mobility compared to the general population, the impact of population mobility on the continuum of HIV services should not be underestimated [44,45]. Hence, designing more tailored treatment programs for different population groups, including KPs, is important for Rwanda to continue to make progress towards the 90-90-90 HIV targets.

Many of the suggestions to improve HIV services among KPs in Rwanda such as counseling, financial support, nutrition support, home visits, peer educator programs, and providing special training to HCPs are consistent with suggestions from other studies as well as the WHO's guidelines on critical enablers for HIV services for KPs [15,22,46,47,48]. Although these suggestions were not new, this study was the first to present documented evidence in Rwanda to support these practices. Therefore, these suggestions should continue to be taken into consideration when designing programs and interventions to address the needs of KPs in HIV services across the country.

The respondents in our study suggested creating separate and safe spaces for KPs as a way to facilitate their access to and engagement with HIV prevention and treatment services. Such suggestions were not new; however, the execution has been met with mixed results. The WHO treatment guidelines for KPs recommended health facilities to create safe environments for KPs either through having separate entrances for them or relocating the KP services to a safe setting [15]. A study conducted in Uganda also showed that HIV patients faced more stigmatization when attending integrated HIV services, as HCPs in integrated services were reluctant to serve HIV positive patients and patients felt that stand-alone services offered more privacy [49]. However, creating separate services for KP could be counterproductive as this could lead to KP facing further stigmatization and discrimination. There have been reported incidences of HIV patients being the targets of stigma, discrimination, and hostility from people who had seen them entering stand-alone HIV units [50,51,52]. A study from Ghana further suggested that stand-alone HIV clinics offered no confidentiality to HIV positive patients, as their HIV status were disclosed to others simply by showing up to these clinics [53]. Thus, further impact analysis is needed, with the considerations of the cultural, social, and legal context of Rwanda, in order to inform the decision on the implementation of this suggestion.

This study unearthed a government-based structural barrier which was not mentioned in other previous studies. Many KPs could not purchase the national health insurance because they were not included in the Ubudehe (social stratification) system. In Rwanda, households were classified into different social stratification categories, ranging from A (high income) to D (low income) and $\mathrm{E}$ (who do not work due to old age or disabilities) [54,55]. This categorization determines how much one should pay for the national health insurance [56]. Ubudehe categories, however, are not available to people who are not married and are always tied to families [56]. When individuals were disowned by their families (which is very common among KPs), they would not have Ubudehe categories, and in turn, would not be able to purchase health insurance. The Rwanda Government revises the Ubudehe categories every three years [57], results of this study present an opportunity for the government to further identify and address gaps hindering the country from approaching universal health coverage and achieve the targets of the National HIV plan, by identifying methods to provide the Ubudehe categories to sole individuals, in order to ensure KPs are not left behind.

\section{Lack of Data on Injection Drug Users and Transgender People}

Our study aimed to investigate the experience of HCPs in providing HIV services to KPs. All our respondents had provided services to MSM and commercial sex workers. However, none had worked with known (self-identified) transgender people and Injection Drug Users (IDUs). The lack of information about these KP groups is concerning and points to a larger issue within the healthcare system. While curbing the infections and transmission of HIV among MSM and sex workers are specifically mentioned, Rwanda's national HIV/AIDS targets do not make mention of transgender people and do not prioritize

Page $14 / 20$ 
interventions among IDUs - because "injection drug use is not present or widely practiced in Rwanda" [5]. However, recent studies have shown that $10 \%$ of transgender women and $9.5 \%$ of IDUs in Kigali were HIV positive $[10,11]$.

There is a need, thus, to revise the current National HIV/AIDS plan to acknowledge the IDUs and transgender population. In order for the country to achieve its national HIV targets and continue making progress towards the 90-90-90 HIV targets, recognizing their presence and creating specific interventions and policies for them are necessary. To effectively curb HIV infections, inclusive strategies and policies for these KP groups, in line with international recommendations and best practices, are needed.

\section{Limitations}

This study was the first in Rwanda to gain the experiences from a diverse group of HCPs about providing HIV services to KPs. However, the results must be viewed in light of its limitations. The study topic is sensitive by nature. Although some of our respondents had been explicit about their personal disapproval against MSM and commercial sex workers, it was possible that some respondents were not expressing their true perspectives, especially if their personal perceptions and attitudes towards KPs were negative or discriminatory.

Our study only included one rural health facility and did not include any private health facility; thus, the results may not reflect the perspectives of all HCPs in Rwanda. However, the findings of our study highlighted some crucial information and suggestions to improve the HIV services for KPs in Rwanda that were not discovered in previous literature.

\section{Conclusion}

HCPs expressed difficulties in providing services to KPs. KPs tend to not adhere to treatment and prevention guidelines. The situation was exacerbated by the structural barriers, their lack of trust in the system, and the discrimination and abuse they faced. Effective treatment approaches that go beyond clinical interventions, including economic and psychosocial support are needed. Assistance from sources, such as NGOs or peer educators trusted by KPs. would help in facilitating the delivery of the services.

Some important policy changes may be needed to improve health outcomes for KPs in Rwanda. Incorporating more inclusive strategies in the national HIV plan and the Ubudehe system could improve access to HIV services for KPs.

\section{Abbreviations}

HCP Health care provider

KP Key population

MSM Men who have Sex with Men

IDUs Injection Drug Users

HIV Human Immunodeficiency Virus

AIDS Acquired immunodeficiency syndrome

\section{Declarations}




\section{Ethics approval and consent to participate:}

This study was approved by the UGHE Institutional Review Board (Protocol \#98). Informed consents were obtained from all participants.

\section{Consent for publication:}

Not applicable.

\section{Availability of data and materials:}

The datasets generated and/or analyzed during the current study are not publicly available due to privacy and confidentiality of information provided by respondents but are available from the corresponding author on reasonable request.

\section{Competing interests:}

The authors declare that they have no competing interests.

\section{Funding:}

This study received no external funding support.

\section{Authors' contributions:}

GI, JMS, SM, and RW conceptualized the project. GI, JMS, and SM created the study proposal. GI collected the data. GI, JMS, $\mathrm{SM}$, and RW analyzed and interpreted the data. GI and RW contributed to writing the manuscript. All authors read and approved the final manuscript.

\section{Acknowledgements:}

We thank all the healthcare providers who participated in this study, and the health facility directors who allowed us to conduct the study within their health centers. We would also like to recognize the support of Gisele Tumukunde and Xavier F. Harelimana during data collection. Lastly, special acknowledgment to Spéciose Nyiraneza for connecting the research team to the health facilities and for helping with the approval processes.

\section{References}

1. Rwanda Biomedical Center, NISR, PEPFAR, CDC, ICAP. Rwanda Population-based HIV Impact Assessment 2018-2019. 2020. https://phia.icap.columbia.edu/wp-content/uploads/2019/10/RPHIA-Summary-Sheet_Oct-2019.pdf. Accessed 19 Jan 2022.

2. Kayirangwa E, Hanson J, Munyakazi L, Kabeja A. Current trends in Rwanda's HIV/AIDS epidemic. Sex Transm Infect 2006;82 Suppl 1:i27-31. https://doi.org/10.1136/sti.2006.019588.

3. Rwanda Biomedical Center. Rwanda Global AIDS Response Progress Report (GARPR) 2014. 2014.

4. Binagwaho A, Farmer PE, Nsanzimana S, Karema C, Gasana M, Ngirabega J de D, et al. Rwanda 20 years on: investing in life. The Lancet 2014;384:371-5. https://doi.org/10.1016/S0140-6736(14)60574-2. 
5. Ministry of Health. National HIV/AIDS Targets 2018-2020-2030. 2015.

https://rbc.gov.rw/IMG/pdf/rwanda_hiv_aids_2020_and_2030_targets.pdf. Accessed 19 Jan 2022.

6. Joint United Nations Program on HIV/AIDS (UNAIDS). New HIV infections increasingly among key populations. 2020. https://www.unaids.org/en/resources/presscentre/featurestories/2020/september/20200928_new-hiv-infectionsincreasingly-among-key-populations. Accessed 19 Jan 2022.

7. Dolan K, Kite B, Black E, Aceijas C, Stimson GV. HIV in prison in low-income and middle-income countries. Lancet Infect Dis 2007;7:32-41. https://doi.org/10.1016/S1473-3099(06)70685-5.

8. Mutagoma M, Samuel MS, Kayitesi C, Gasasira AR, Chitou B, Boer K, et al. High HIV prevalence and associated risk factors among female sex workers in Rwanda. Int J STD AIDS 2017;28:1082-9.

https://doi.org/10.1177/0956462416688137.

9. Ntale RS, Rutayisire G, Mujyarugamba P, Shema E, Greatorex J, Frost SDW, et al. HIV seroprevalence, self-reported STIs and associated risk factors among men who have sex with men: a cross-sectional study in Rwanda, 2015. Sex Transm Infect 2019;95:71-4. https://doi.org/10.1136/sextrans-2017-053311.

10. Twahirwa Rwema JO, Lyons CE, Herbst S, Liestman B, Nyombayire J, Ketende S, et al. HIV infection and engagement in HIV care cascade among men who have sex with men and transgender women in Kigali, Rwanda: a cross-sectional study. J Int AIDS Soc 2020;23:e25604. https://doi.org/10.1002/jia2.25604.

11. Twahirwa Rwema JO, Nizeyimana V, Menezes NP, Okonkwo NE, Mazzei AA, Muhirwa S, et al. Injection Drug use Practices and HIV infection among People Who Inject Drugs in Kigali, Rwanda. MedRxiv 2021:2021.08.05.21261564. https://doi.org/10.1101/2021.08.05.21261564.

12. United States Agency for International Development. Key Populations: Achieving Equitable Access to End AIDS. 2021. https://www.usaid.gov/global-health/health-areas/hiv-and-aids/technical-areas/key-populations. Accessed 19 Jan 2022.

13. Joint United Nations Program on HIV/AIDS (UNAIDS). The need to scale up HIV programmes for key populations in western and central Africa. 2018.

https://www.unaids.org/en/resources/presscentre/featurestories/2018/december/western-and-central-africa. Accessed 19 Jan 2022.

14. Macdonald V, Verster A, Baggaley R. A call for differentiated approaches to delivering HIV services to key populations. J Int AIDS Soc 2017;20:21658. https://doi.org/10.7448/IAS.20.5.21658.

15. World Health Organization. Consolidated guidelines on HIV prevention, diagnosis, treatment and care for key populations. 2016 update. Geneva: World Health Organization; 2016.

16. Decker MR, Lyons C, Billong SC, Njindam IM, Grosso A, Nunez GT, et al. Gender-based violence against female sex workers in Cameroon: prevalence and associations with sexual HIV risk and access to health services and justice. Sex Transm Infect 2016;92:599-604. https://doi.org/10.1136/sextrans-2015-052463.

17. Shumbusho F, Griensven J van, Lowrance D, Turate I, Weaver MA, Price J, et al. Task Shifting for Scale-up of HIV Care: Evaluation of Nurse-Centered Antiretroviral Treatment at Rural Health Centers in Rwanda. PLOS Med 2009;6:e1000163. https://doi.org/10.1371/journal.pmed.1000163.

18. Franke MF, Kaigamba F, Socci AR, Hakizamungu M, Patel A, Bagiruwigize E, et al. Improved retention associated with community-based accompaniment for antiretroviral therapy delivery in rural Rwanda. Clin Infect Dis Off Publ Infect Dis Soc Am 2013;56:1319-26. https://doi.org/10.1093/cid/cis1193.

19. Rich ML, Miller AC, Niyigena P, Franke MF, Niyonzima JB, Socci A, et al. Excellent clinical outcomes and high retention in care among adults in a community-based HIV treatment program in rural Rwanda. J Acquir Immune Defic Syndr 1999 2012;59:e35-42. https://doi.org/10.1097/QAl.0b013e31824476c4.

20. Nsanzimana S, Prabhu K, McDermott H, Karita E, Forrest JI, Drobac P, et al. Improving health outcomes through concurrent HIV program scale-up and health system development in Rwanda: 20years of experience. BMC Med 2015;13:216. https://doi.org/10.1186/s12916-015-0443-z.

Page $17 / 20$ 
21. Yannessa JF, Reece M, Basta TB. HIV Provider Perspectives: The Impact of Stigma on Substance Abusers Living with HIV in a Rural Area of the United States. AIDS Patient Care STDs 2008;22:669-75.

https://doi.org/10.1089/apc.2007.0151.

22. Mutambo C, Hlongwana K. Healthcare Workers' Perspectives on the Barriers to Providing HIV Services to Children in Sub-Saharan Africa. AIDS Res Treat 2019;2019:e8056382. https://doi.org/10.1155/2019/8056382.

23. Kambutse I, Igiraneza G, Ogbuagu O. Perceptions of HIV transmission and pre-exposure prophylaxis among health care workers and community members in Rwanda. PLOS ONE 2018;13:e0207650. https://doi.org/10.1371/journal.pone.0207650.

24. Ingabire R, Parker R, Nyombayire J, Ko JE, Mukamuyango J, Bizimana J, et al. Female sex workers in Kigali, Rwanda: a key population at risk of HIV, sexually transmitted infections, and unplanned pregnancy. Int J STD AIDS 2019;30:55768. https://doi.org/10.1177/0956462418817050.

25. Sidibe T, Golin C, Turner K, Fray N, Fogel C, Flynn P, et al. Provider Perspectives Regarding the Health Care Needs of a Key Population: HIV-infected Prisoners After Incarceration. J Assoc Nurses AIDS Care 2015;26:556-69.

https://doi.org/10.1016/j.jana.2015.05.001.

26. Bashir F, Ba Wazir M, Schumann B, Lindvall K. The realities of HIV prevention. A closer look at facilitators and challenges faced by HIV prevention programmes in Sudan and Yemen. Glob Health Action 2019;12:1659098. https://doi.org/10.1080/16549716.2019.1659098.

27. Stobo JD, Kohen JJ, Kimball HR, LaCombe MA, Schechter GP, Blank LL, et al. Project Professionalism. Philadelphia, PA: American Board of Internal Medicine; 2001.

28. Matovu JKB, Musinguzi G, Kiguli J, Nuwaha F, Mujisha G, Musinguzi J, et al. Health providers' experiences, perceptions and readiness to provide HIV services to men who have sex with men and female sex workers in Uganda - a qualitative study. BMC Infect Dis 2019;19:214. https://doi.org/10.1186/s12879-019-3713-0.

29. Health Development Innitiative. CAN ANYBODY HEAR US? Exploring the realities of being lesbian, gay or bisexual in Rwanda. 2015. http://hdirwanda.org/wp-content/uploads/2019/03/LGBTI-BOOKLET-CAN-ANYBODY-HEAR-US1.pdf. Accessed 19 Jan 2022.

30. Adedimeji A, Sinayobye J d'Amour, Asiimwe-Kateera B, Chaudhry J, Buzinge L, Gitembagara A, et al. Social contexts as mediator of risk behaviors in Rwandan men who have sex with men (MSM): Implications for HIV and STI transmission. PLOS ONE 2019;14:e0211099. https://doi.org/10.1371/journal.pone.0211099.

31. Shangani S, Naanyu V, Operario D, Genberg B. Stigma and Healthcare-Seeking Practices of Men Who Have Sex with Men in Western Kenya: A Mixed-Methods Approach for Scale Validation. AIDS Patient Care STDs 2018;32:477-86. https://doi.org/10.1089/apc.2018.0101.

32. Maleke K, Daniels J, Lane T, Struthers H, McIntyre J, Coates T. How social stigma sustains the HIV treatment gap for MSM in Mpumalanga, South Africa. Glob Health Promot 2019;26:6-13. https://doi.org/10.1177/1757975917737509.

33. Shangani S, Naanyu V, Mwangi A, Vermandere H, Mereish E, Obala A, et al. Factors associated with HIV testing among men who have sex with men in Western Kenya: a cross-sectional study. Int J STD AIDS 2017;28:179-87. https://doi.org/10.1177/0956462416638967.

34. King R, Sebyala Z, Ogwal M, Aluzimbi G, Apondi R, Reynolds S, et al. How men who have sex with men experience HIV health services in Kampala, Uganda. BMJ Glob Health 2020;5:e001901. https://doi.org/10.1136/bmjgh-2019-001901.

35. Micheni M, Kombo BK, Secor A, Simoni JM, Operario D, van der Elst EM, et al. Health Provider Views on Improving Antiretroviral Therapy Adherence Among Men Who Have Sex with Men in Coastal Kenya. AIDS Patient Care STDs 2017;31:113-21. https://doi.org/10.1089/apc.2016.0213.

36. Duby Z, Nkosi B, Scheibe A, Brown B, Bekker L-G. 'Scared of going to the clinic': Contextualising healthcare access for men who have sex with men, female sex workers and people who use drugs in two South African cities. South Afr J HIV Med 2018;19:701. https://doi.org/10.4102/sajhivmed.v19i1.701. 
37. Beyrer C, Crago A-L, Bekker L-G, Butler J, Shannon K, Kerrigan D, et al. An Action Agenda for HIV and Sex Work. Lancet 2015;385:287-301. https://doi.org/10.1016/S0140-6736(14)60933-8.

38. Lall P, Lim SH, Khairuddin N, Kamarulzaman A. Review: An urgent need for research on factors impacting adherence to and retention in care among HIV-positive youth and adolescents from key populations. J Int AIDS Soc 2015;18:19393. https://doi.org/10.7448/IAS.18.2.19393.

39. Lancaster KE, Cernigliaro D, Zulliger R, Fleming PF. HIV care and treatment experiences among female sex workers living with HIV in sub-Saharan Africa: A systematic review. Afr J AIDS Res 2016;15:377-86. https://doi.org/10.2989/16085906.2016.1255652.

40. Ogunbajo A, Kershaw T, Kushwaha S, Boakye F, Wallace-Atiapah N-D, Nelson LE. Barriers, Motivators, and Facilitators to Engagement in HIV Care Among HIV-Infected Ghanaian Men Who have Sex with Men (MSM). AIDS Behav 2018;22:82939. https://doi.org/10.1007/s10461-017-1806-6.

41. Januraga PP, Reekie J, Mulyani T, Lestari BW, Iskandar S, Wisaksana R, et al. The cascade of HIV care among key populations in Indonesia: a prospective cohort study. Lancet HIV 2018;5:e560-8. https://doi.org/10.1016/S23523018(18)30148-6.

42. Bowring AL, Ketende S, Rao A, Njindam IM, Decker MR, Lyons C, et al. Characterising unmet HIV prevention and treatment needs among young female sex workers and young men who have sex with men in Cameroon: a crosssectional analysis. Lancet Child Adolesc Health 2019;3:482-91. https://doi.org/10.1016/S2352-4642(19)30123-3.

43. Henderson M. Case examples of programmes serving the needs of key populations. In: Consolidated Guidelines on HIV Prevention, Diagnosis, Treatment and Care for Key Populations. 2016 update. https://www.ncbi.nlm.nih.gov/books/NBK379687/. Accessed 19 Jan 2022.

44. Taylor BS, Garduño LS, Reyes EV, Valiño R, Rojas R, Donastorg Y, et al. HIV Care for Geographically Mobile Populations. Mt Sinai J Med J Transl Pers Med 2011;78:342-51. https://doi.org/10.1002/msj.20255.

45. Camlin CS, Cassels S, Seeley J. Bringing population mobility into focus to achieve HIV prevention goals. J Int AIDS Soc 2018;21:e25136. https://doi.org/10.1002/jia2.25136.

46. van der Elst EM, Smith AD, Gichuru E, Wahome E, Musyoki H, Muraguri N, et al. Men who have sex with men sensitivity training reduces homoprejudice and increases knowledge among Kenyan healthcare providers in coastal Kenya. J Int AIDS Soc 2013;16:18748. https://doi.org/10.7448/IAS.16.4.18748.

47. Hatcher AM, Turan JM, Leslie HH, Kanya LW, Kwena Z, Johnson MO, et al. Predictors of linkage to care following community-based HIV counseling and testing in rural Kenya. AIDS Behav 2012;16:1295-307. https://doi.org/10.1007/s10461-011-0065-1.

48. Bhattacharjee P, Musyoki H, Prakash R, Malaba S, Dallabetta G, Wheeler T, et al. Micro-planning at scale with key populations in Kenya: Optimising peer educator ratios for programme outreach and HIV/STI service utilisation. PLOS ONE 2018;13:e0205056. https://doi.org/10.1371/journal.pone.0205056.

49. Zakumumpa H, Rujumba J, Kwiringira J, Kiplagat J, Namulema E, Muganzi A. Understanding the persistence of vertical (stand-alone) HIV clinics in the health system in Uganda: a qualitative synthesis of patient and provider perspectives. BMC Health Serv Res 2018;18:690. https://doi.org/10.1186/s12913-018-3500-4.

50. Uebel K, Guise A, Georgeu D, Colvin C, Lewin S. Integrating HIV care into nurse-led primary health care services in South Africa: a synthesis of three linked qualitative studies. BMC Health Serv Res 2013;13:171. https://doi.org/10.1186/14726963-13-171.

51. Bond V, Nomsenge S, Mwamba M, Ziba D, Birch A, Mubekapi-Musadaidzwa C, et al. "Being seen" at the clinic: Zambian and South African health worker reflections on the relationship between health facility spatial organisation and items and HIV stigma in 21 health facilities, the HPTN 071 (PopART) study. Health Place 2019;55:87-99. https://doi.org/10.1016/j.healthplace.2018.11.006.

52. Topp SM, Chipukuma JM, Chiko MM, Matongo E, Bolton-Moore C, Reid SE. Integrating HIV treatment with primary care outpatient services: opportunities and challenges from a scaled-up model in Zambia. Health Policy Plan 2013;28:347- 
57. https://doi.org/10.1093/heapol/czs065.

53. Dapaah JM, Senah KA. HIV/AIDS clients, privacy and confidentiality; the case of two health centres in the Ashanti Region of Ghana. BMC Med Ethics 2016;17:41. https://doi.org/10.1186/s12910-016-0123-3.

54. Ntirenganya E. Where do you fall in the new Ubudehe categories? New Times. 2020.

https://www.newtimes.co.rw/news/where-do-you-fall-new-ubudehe-categories. Accessed 19 Jan 2022.

55. Bizimungu J. New Ubudehe categories: What you need to know. New Times. 2020.

https://www.newtimes.co.rw/news/new-ubudehe-categories-what-you-need-know. Accessed 19 Jan 2022.

56. Ministry of Local Government. NST-1 Social Protection Sector Strategic Plan (SP-SPP) 2018/19-2023/24. 2018. https://www.minaloc.gov.rw/fileadmin/user_upload/Minaloc/Sector_docs/Social_Protection_Sector_Strategic_Plan.pdf. Accessed 19 Jan 2022.

57. Dushimimana M-A. Ubudehe categories to be reviewed. New Times. 2019. https://www.newtimes.co.rw/news/ubudehecategories-be-reviewed. Accessed 19 Jan 2022. 